\title{
Combined interhemispheric translamina terminalis and pterional approach for a dorsum sellae meningioma
}

\author{
Shinya Suematsu, MD, Hideaki Ono, MD, PhD, Tomohiro Inoue, MD, PhD, \\ and Akira Tamura, MD, PhD
}

Department of Neurosurgery, Fuji Brain Institute and Hospital, Shizuoka, Japan

This video demonstrates a surgical technique of resecting dorsum sellae meningioma using a combined interhemispheric translamina terminalis approach and pterional approach with clinoidectomy. The tumor, $5 \mathrm{~cm}$ in maximum diameter, originated from the dorsum sellae, compressed the third ventricle and the midbrain, and displaced the pituitary stalk ventrally. Feeding arteries of the tumor were bilateral meningohypophyseal trunks, mainly from the right side. The authors performed devascularization of the tumor via a right pterional approach following frontotemporal craniotomy, and debulking of the tumor via an interhemispheric translamina terminalis approach following bifrontal craniotomy. These procedures with two separate craniotomies enabled safe and effective resection of the tumor.

The video can be found here: https://youtu.be/DEnKOC5zQ_M.

KEYWORDS interhemispheric translamina terminalis approach; pterional approach; clinoidectomy; skull base; dorsum sellae meningioma 